\title{
Demand Analysis of China's Engineering Science and Technology for Economic and Social Development to 2035
}

\author{
Luan Enjie ${ }^{1}$, Yuan Jianhua ${ }^{2}$, Man Xuan², Zhang Zhang ${ }^{2}$ \\ 1. State Administration of Science, Technology and Industry for National Defence, the People's Republic of China, Beijing 100088, China \\ 2. China Aerospace Academy of Systems Science and Engineering, Beijing 100048, China
}

\begin{abstract}
The objective of this analysis is to link China's economic and social development with its engineering science and technology demands. This article introduces the background and methods of demand analysis in China and abroad. The analysis is based on interviews with and surveys on core experts on economic and social development, along with other methods, to depict six visions of China's economic and social development to 2035 and highlight the demands for engineering science and technology.
\end{abstract}

Keywords: 2035; visions; demand; economic and social development; engineering science and technology

\section{Introduction}

In 2015, the Chinese Academy of Engineering and National Natural Science Foundation of China co-initiated "Research on China's Engineering Science and Technology Development Strategy 2035." This was to deepen research on China's future development strategy for engineering science and technology. The research was conducted in 2009 and based on the report on "Research on China's Medium and Long-Term Development Strategy for Engineering Science and Technology for 2030," which combined the latest research achievements domestically and internationally. The study set up a demand analysis panel for the first time, the results of which were used to propose demands for engineering science and technology for China's economic and social development by 2035 . This supported the development considerations and future technology options for China's engineering science and technology.

Demand analysis is the pioneer of strategic research, which projects the economic and social development visions and demands of the engineering science and technology industries, supporting the systematic planning and forward deployment of engineering science and technology nationally. This paper begins with China's 2035 economic and social development visions, employs research methods such as core personnel interviews and a Delphi questionnaire and "iteration," and proposes the requirements for engineering science and technology needed for economic and social development.

\section{Domestic and international referential experiences regarding a demand analysis for engineering science and technology}

\subsection{Demand analysis in international strategy research on the development of engineering science and technology}

In recent years, when formulating engineering science and technology development strategies, countries worldwide have attached increasing importance to demands for economic and social development and emphasize using visions-oriented economic and social development demands as an important reference.

Received Date: 25 December 2016; revised Date: 30 December 2016

Corresponding author: Man Xuan, China Aerospace Academy of Systems Science and Engineering, Engineer. Major research field is system engineering and industry development. E-mail: manxuan2008@126.com

Funding program: CAE Advisory Project “Research on China's Engineering Science and Technology Development Strategy 2035” (2015-ZD-14); National Natural Science Foundation Project of China (L152400021)

Chinese version: Strategic Study of CAE 2017, 19 (1): 021-026

Cited item: Luan Enjie et al. Demand Analysis of China's Engineering Science and Technology for Economic and Social Development to 2035. Strategic Study of CAE, https://doi.org/10.15302/J-SSCAE-2017.01.004 
2.1.1 Demand analysis in strategy research in Japan on the development of engineering science and technology

Japan has conducted demand analysis for more than 20 years. It was first introduced in the sixth technology foresight. As such, the country has accumulated rich experience in this regard, as shown in Table $1[1,2]$. In the tenth technology foresight, the conclusions of demand analysis center on seven fields including manufacturing, population, city, and food. Each field includes 8 to 12 topics (63 topics in total) [3].

2.1.2 Demand analysis in strategy research in Europe on the development of engineering science and technology

Some European countries such as Britain and Germany first conducted demand analysis in development strategy research on engineering science and technology in the 1990s.

From 1999 to 2001, Britain conducted the second technology forecast, which focused on innovation in science and technology and society as well as on opportunities for Britain's economic and social development based on innovation. In the third technology forecast in 2002 , activities aimed to solve social problems through the advancement of technology [4,5]. The research involved a wide range of personnel. For example, 300 experts, business people, and policymakers from 25 countries were involved in the 2050 prediction analysis of the British manufacturing industry [6].

Germany was the first country in Europe to carry out institutionalized technology foresight activities, which opened the way for European governments to carry out these activities. In the technology forecast activities conducted during 2012-2016, Germany employed extensive opinion surveys to determine the life visions of the public. Based on the results, technology forecast workers formulated plans for the state's technology development in the future from the perspective of considering how to meet citizens' expectations for their lives [7].

\subsection{Primary methods for conducting demand analysis in China's development strategy research on engineering science and technology}

Although China was relatively late to introduce demand analysis in development strategy research on engineering science and technology, the explorations were valuable.

2.2.1 Research on China's economic and social development visions in the late 12th Five-Year Plan period

To develop China's 12th Five-Year Plan for science and technology development, the Chinese Academy of Science and Technology for Development conducted research on the country's economic and social development visions and the future [8] Several research stages were implemented as follows: (1) considering China's economic and social development vision. Based on research on bibliographical information and on-site interviews, symposiums, questionnaire surveys, expert consultations, statistical analysis, and other methods, a vision for the future was formulated through normative research and forecasting methods. Furthermore, references to the opinions and suggestions of experts in the field, government, professionals in the industrial economy, and representatives of the public were combined with rigorous statistical analysis. (2) Refining the demands for science and technology for economic and social development. This stage sought to understand the demands for science and technology from the perspective of the vision for economic and social de-

Table 1. Summary of Japan's demand analysis practices.

\begin{tabular}{|c|c|}
\hline Demand analysis & Summary of practices \\
\hline Demand analysis in the sixth technology forecast & $\begin{array}{l}\text { After the technology forecast and survey, demands research was formulated. The main methods } \\
\text { included: } \\
\text { 1. Public opinion surveys to understand people's medium and long-term demands } \\
\text { 2. Analyzing key technologies from the perspective of social and economic demands }\end{array}$ \\
\hline Demand analysis in the seventh technology forecast & $\begin{array}{l}\text { 1. Evaluating the importance of various social and economic demands } \\
\text { 2. Evaluating the correlation between technology projects in various technology areas and these } \\
\text { demands, and evaluating the contributions of technology to address the demands }\end{array}$ \\
\hline Demand analysis in the eighth technology forecast & $\begin{array}{l}\text { 1. Based on the types of demands highlighted in the seventh technology forecast report, a } \\
\text { network questionnaire survey was conducted to gather the opinions of } 4000 \text { experts, members } \\
\text { of the public, and commercial leaders to formulate a list of social and economic demands } \\
\text { 2. The contributions of technology to the demands in the future were evaluated through an } \\
\text { analysis of the correlation between technology and the demands. Questionnaire surveys were } \\
\text { also employed. }\end{array}$ \\
\hline Demand analysis in the ninth technology forecast & $\begin{array}{l}\text { 1. A scenario prediction method was applied to predict the demands for technology for } \\
\text { economic and social development and visions in the future } \\
\text { 2. Scenario analysis committees were established and experts asked to predict future scenarios }\end{array}$ \\
\hline Demand analysis in the tenth technology forecast & $\begin{array}{l}\text { This demand analysis was a study on science and technology that aimed to achieve the structure } \\
\text { and visions of a future society. The main methods included: } \\
\text { 1. Conducting surveys related to future social visions through seminars that included numerous } \\
\text { participants } \\
\text { 2. Creating multiple-option research based on integrating related science and technology groups } \\
\text { and achievements based on visions }\end{array}$ \\
\hline
\end{tabular}


velopment to clarify the direction of science and technology development. (3) Clarifying research conclusions and making recommendations for policy. Finally, the research has six aspects regarding the economic and social development visions, and 13 for the scientific and technological needs of this economic and social development.

2.2.2 Demand analysis in China's technology forecast research for the next 20 years

The Institute of Policy and Management of Chinese Academy of Sciences analyzed visions and demands to achieve "China's technology forecast in the next 20 years." There were two research stages: (1) development of the visions analysis. A development trends forecast, indicator forecast, and other methods should be performed to determine China's economic and social development views for 2020. Major problems to be solved were pointed out from the perspectives of globalization, industrialization, informatization, urbanization, and the consumer and circulation society. (2) Highlight the demands for science and technology. The strategic demands for science and technology development were identified for holistically constructing a well-off society. This began by considering the development vision of the "globalization and informatization society," "industrialization society," "urbanization society," and the "circulation" and "consumer" societies [9].

\section{Summary: demand analysis of engineering science and technology for China's economic and social development by 2035}

\subsection{The idea}

Essentially, the demand analysis began from a macroscopic viewpoint and advanced in stages. First, based on access to massive data and through questionnaire surveys and interviews with experts, China's economic and social development visions for various aspects of life were collected to determine the country's economic and social development views for 2035. Second, according to China's economic and social development visions for 2035, interviews with experts in economics, society, as well as the engineering science and technology industries were conducted. The purpose was to propose an alternative economic and social development list of demands to support the achievement of China's 2035 economic and social development vision. Third, the demands for the engineering science and technology needed for China's 2035 economic and social development were proposed by projecting these demands to the engineering science and technology industries and through interviews with experts in these industries. The purpose was to meet the demands for China's 2035 economic and social development, as shown in Fig. 1.

\subsection{Research steps}

The demand analysis research was performed in three steps, as shown in Fig. 2.

\subsubsection{Collecting information on the visions}

Collecting notions pertaining to the visions involved three steps: (1) data collection, analysis, and sorting. The data included reports on the status of development of China's economy, society, and engineering science and technology industry. Furthermore, reports on the opportunities and challenges in development over the next 20 years and long-term development planning research were included. The focus was on relevant data on the trends in the development of the economy, society, and engineering science and technology. (2) Information on China's 2035 economic and social development vision was collected from experts for all aspects of life through interviews, questionnaire surveys, and other methods. (3) China's 2035 economic and social development vision was summarized and refined, and views considered based on interviews with experts and questionnaire surveys.

3.2.2 Determining China's 2035 economic and social development list of demands

The list of demands was set out in the field based on development trends and the visions for the economy and society for the next 20 years. Based on the visions analysis, research program teams drafted an alternative list of demands. After this, further interviews were conducted with experts on China's economy,

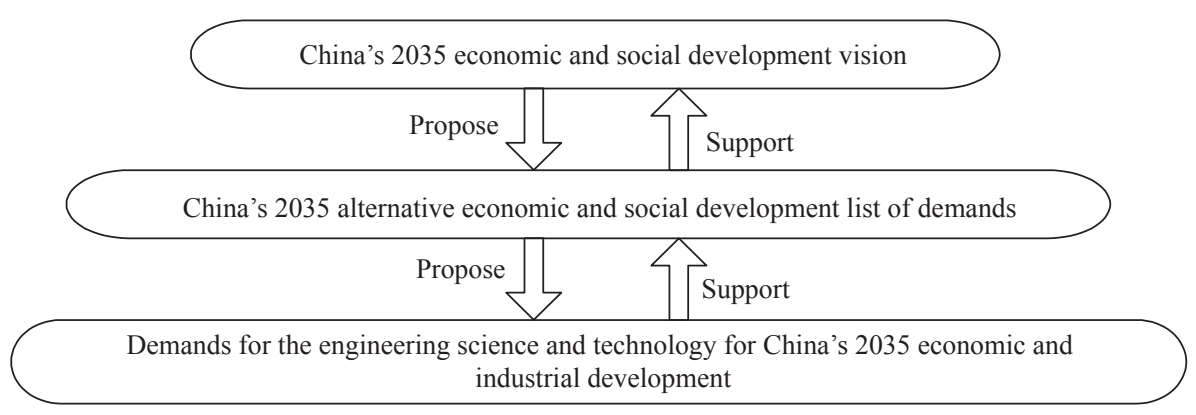

Fig. 1. Basis of demand analysis research. 
Collection of vision

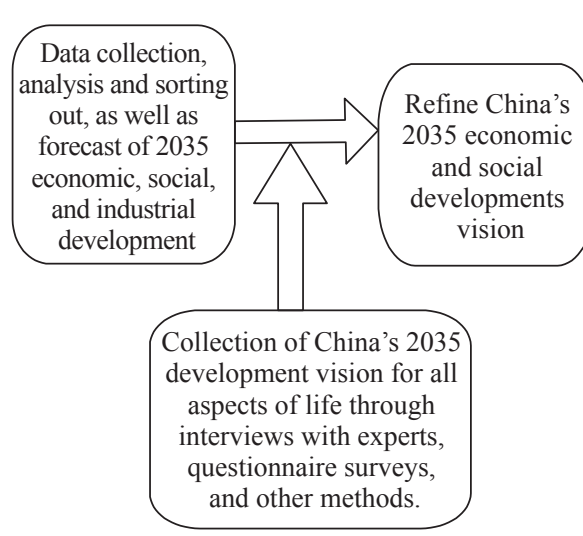

Determine China's economic and social development list of demands

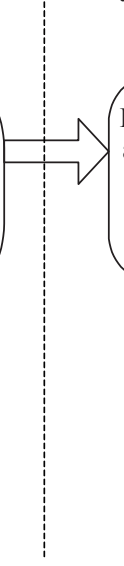

Discuss alternative list of demands through interviews with experts, symposia, and other methods

Fig. 2. Steps in demand analysis research.

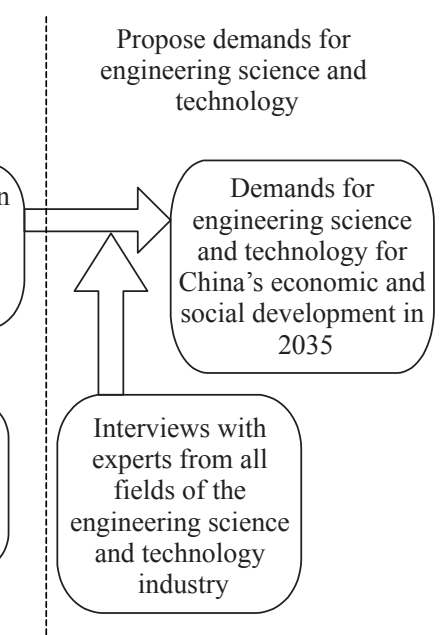

society, and engineering science and technology, and symposia held to confirm the list.

\subsubsection{Proposing the demands for engineering science and technology}

China's 2035 alternative economic and social development list of demands was proposed to all engineering science and technology industries. It was based on interviews with experts in the engineering science and technology industries and the symposia.

\section{China's economic and social development visions for 2035}

This research helped to establish China's six major economic and social development visions for 2035 .

\subsection{Vision 1: a globalized China}

By 2035, China's social and economic globalization will enter a new stage of historical development in which the country will have relatively high international prestige and influence. By then, China will contribute to the maintenance of international societal peace, the prosperity of the world economy, and be a powerful engine of world economic growth to the benefit of relevant countries. By then, China's science and technology progress will also benefit all mankind, because of significantly deepened integration with international advanced technology. Furthermore, the globalized dissemination of China's culture will present contemporary China in three dimensions.

\subsection{Vision 2: China will be ranked as a high-income country}

In the next two decades, by continuously adjusting its structure, China will rank among other high-income countries. By 2035, China's national economy will run efficiently overall. Science and technology engineering innovation will become a new driving force of economic development, helping the economy to improve until attaining its status at the high end of the income scale. Furthermore, an efficient industrial structure will emerge. Per capita income will achieve the level of developed economies, and an increasing number of people will be classified in the middle-income class, enabling a more reasonable income distribution.

\subsection{Vision 3: intelligent China}

By 2035, China's economy and society will become intelligent in all aspects, while the manufacturing industry will attain the world manufacturing power level. In addition, intelligent medical services will be popularized in the lives of ordinary people, and the concept "health first and prevention matters" will be deeply rooted in people's minds. Furthermore, intelligent education will become a new trend in education information development, which may advance the equal development of education. At that time, an intelligent transportation system will be developed, which may significantly improve the happiness index of residents.

\subsection{Vision 4: a sustainable China}

In the next two decades, China will implement its concept of ecological civilization to form the country's blueprint. This will contribute towards achieving a green and sustainable China. By 2035, China's carbon dioxide emissions will halve. Meanwhile, China will significantly improve the efficiency of resource utilization and optimize the energy structure. Moreover, the country will achieve green development, cycle development, and low carbon development. This will advance and improve the ecological environment, realizing the construction of a beautiful China. Finally, the value of an ecological civilization will be popularized in society, and it is envisioned that the public will develop a green lifestyle. 


\subsection{Vision 5: a harmonious China}

In 2035, a more harmonious China will emerge in the east of the world. The concept of health will be integrated into all policies to promote the fact that all people construct a healthy China together and share the results thereof. Furthermore, health and health services for the entire lifecycle will materialize, and people are expected to have an average life expectancy of 80 years. In addition, citizens will enjoy higher quality and more equitable education resources. Finally, China will become more harmonious and governed by law.

\subsection{Vision 6: a safe China}

In 2035, the country will become safe, with a strong national defense force that can effectively safeguard national security and development interests. By then, China will own a sound public security system, with a strong ability to deal with emergencies and implement risk prevention and control.

\section{Demands for engineering science and technology for China's economic, social, and industrial development for $\mathbf{2 0 3 5}$}

To realize the visions for economic and social development, engineering science and technology is a key factor. Insights into the demands for the development of engineering science and technology from the perspective of the visions for economic and social development specify the direction of development. This research proposes 37 demands for engineering science and technology for China's economic and social development, which are classified into the following nine categories.

\subsection{Optimize the industrial structure to boost industrial transformation and upgrading}

To boost and upgrade China's industrial transformation in the next two decades years and meet demands for the country's industrial development by 2035 , it is important to increase the added value of traditional industries, develop strategic emerging industries, and improve the quality of products. For engineering science and technology, the following demands for development for 2035 are proposed: (1) to comprehensively improve the level of industrial cleaner production technology to reduce pollution at the source and enhance core industrial competitiveness; (2) develop new material and additive manufacturing technologies to improve the ratio of low-energy consumption, environmental protection, and high-efficiency industry chains in the national economy; (3) establish intelligent technology and production systems to develop the industrial robot industry and create new made-in-China advantages; and (4) promote the development of the manufacturing industry's service-related technologies to boost China's overall industrial upgrading.

\subsection{Break through key technologies to safeguard national defense security}

Each country has its own national defense system. "No country can survive without national defense and without soldiers, people cannot live in peace." As long as countries exist, strong national defense that can effectively safeguard national security interests and development interests is needed. The following demands for the development of China's engineering science and technology for 2035 are proposed: (1) to accelerate the development of technologies for high-performance computing, cyber network security, and sensing to lead the competition in the international information field; (2) construct systems for economical and practical space transportation, space-air-ground integrated information interconnection, and deep space exploration engineering to harness the technology of quantum navigation and positioning and support the construction of space power; and (3) develop high-end scientific instruments and related technologies as the foundation of industry development.

\subsection{Optimize the energy structure to build a beautiful ecological environment}

In the next two decades years, China's population and economic growth in the process of industrialization and urbanization will rapidly increase energy and resource demands and produce a large volume of pollution and greenhouse gas emissions. Thus, structural adjustment and technological progress will become primary means to save energy and reduce emissions. For economic and social development, including development speed and structure, the restrictions of a limited growth capacity of energy resources and the sustainable carrying capacity of the environment must be considered. Applying the demands for the development of the energy and environment arena to engineering science and technology, the following demands for China's development for 2035 are proposed: (1) to improve the traditional rate of output and utilization efficiency and develop new energy technology to ensure the safety, high efficiency, and environmental protection of energy output; (2) accelerate the development of pollution prevention and control technologies, build a technical system for environmental protection and restoration, and develop a beautiful ecological environment; and (3) promote the development of recycling and ecological technology for recycling production.

\subsection{Construct a marine power system to protect marine rights and interests}

By applying the demands for the development of the marine environment, the following demands for China's development 
of engineering science and technology for 2035 are proposed: (1) to construct space weather and marine information coprosperity service engineering to achieve a global threedimensional ocean environment monitoring, prediction, and early warning system to actively build knowledge on the oceans and ensure the safety of various maritime operations and activities; (2) develop technology to explore and exploit submarine and marine biological resources, as well as to comprehensively utilize marine water resources and marine energy, and expand the scale of the marine economy; and (3) develop technologies related to marine engineering equipment to safeguard all marine development activities to actively build knowledge on the oceans.

\subsection{Safeguard national food security to promote the sustainable development of agriculture}

By 2035, China's agricultural production capacity will stabilize. This requires attaining the overall capacity of agricultural production for domestic and international markets to realize the sustainable development of agriculture. By applying the demands for agricultural development to engineering science and technology, the following demands for China's development for 2035 are proposed: (1) to develop agricultural biotechnology to improve the capacity of sustainable agricultural production; (2) construct modern agricultural engineering to fully mechanize most agricultural production and achieve intelligent agricultural production; and (3) promote the production of agricultural products and develop information engineering for the circulation field to ensure food safety.

\subsection{Promote the construction of traffic and transportation infrastructure to meet the need for efficient and safe travel}

The construction of safe, convenient, efficient, and comprehensive traffic and transportation systems is an urgent demand for the development of China. By applying the demands for the development of traffic and transportation to engineering science and technology, the following demands for China's development for 2035 are proposed: (1) to expand key technologies of land, sea, and air traffic and transportation tools to safeguard national economic development and national defense security; (2) comprehensively improve the level of integrated transportation technology and develop key technologies for new transportation systems to meet demands for the construction of intelligent transport; and (3) enhance an accessible, smooth, and efficient transportation network capacity to establish convenient and efficient security safeguard systems.

\subsection{Expedite the process of urbanization to advance the integration of urban and rural areas}

It is important that "the process of urbanization is nearing completion" in terms of the overall efficient operation of the economy in the next 20 years. It is also an important demand for China's economic development by 2035. By applying this demand to engineering science and technology, the following demands for China's development by 2035 are proposed: (1) to vigorously develop key technologies to enhance and redevelop the functions of urban central areas to promote China's urbanization process; (2) develop key technologies for new highperformance architectures to achieve "prenatal and postnatal care" and the "health and longevity" of civil structural engineering; and (3) develop an urban ubiquitous sensing network and exploit big data analysis and decision-making technology and its integration and data mining technology to construct wisdom cities.

\subsection{Cope with a super aging society to safeguard people's} health

By 2035, China will be a super aging society. By then, with continuous economic and societal development, people's requirements for health will increase. To deal with the super aging society, improving people's health is an urgent demand for China's economic and social development. Thus, the following demands for China's engineering science and technology by 2035 are proposed: (1) to develop accurate diagnosis and curative effect evaluation technology to improve regenerative and precision medicine to the international standard; (2) identify key technologies for new drug discovery and research and pharmaceutical engineering, and develop technology related to traditional Chinese medicine to safeguard human health; (3) establish health-related big data and an intelligent health management system for communities, and accelerate the development of chronic disease prevention and control engineering as well as key treatment technologies; (4) develop technology related to geriatric medicine to technically support population aging; (5) continuously optimize the infertility treatment system to promote China's prenatal and postnatal care and the continuous improvement of population quality; and (6) develop disease prevention and control technology, develop key technologies to cope with biological safety, and improve the ability to deal with new, sudden infectious diseases.

\subsection{Improve risk prevention and control as well as response capabilities to safeguard public safety}

It is an urgent demand for the development of China's public security to build a comprehensive public security network with risk assessment, prevention, monitoring, emergency handling, and other abilities. Attention must focus on public opinion and safety and the safety of hazardous chemicals, as well as on developing anti-terrorism technology. By applying the demands for public security development to engineering 
science and technology, the following demands for China's development by 2035 are proposed: (1) to construct quantitative, standardized, integrated, and systematic risk assessment and prevention systems to achieve cross-field and cross-industry risk assessment and management of the whole chain; (2) construct leading monitoring, prediction, and early warning technology and develop comprehensive emergency rescue technology to ensure social security; (3) develop comprehensive public security safeguard technology to provide scientific and technological support to improve the public security system, construct resilient cities, and implement China's major national strategies; (4) construct traffic safety systems with safety and reliability functions; (5) develop safety technology for hazardous chemicals in each link of the lifecycle; (6) research basic theories and models, mechanisms, rules, key technologies, and methods of internet group gathering, information dissemination, behavior evolution, and other aspects to solve problems related to public opinion and security; (7) develop anti-terrorism technologies; (8) construct whole-chain and large-scale water security management and intelligence networks; and (9) build a large and complete power grid security defense system to form a security maintenance system to ensure the safe, stable, and economic operation of power grids.

\section{Countermeasures and recommendations for promoting demand analysis research}

At present, in the medium and long-term development strategy research on engineering science and technology, demand analysis based on the visions for economic and social development is in its initial stage. Further exploration and practice is needed. To better carry out a demand analysis, the following recommendations are proposed.

\subsection{Attract more economic and social experts, government officials, entrepreneurs, and members of the public to participate in a demand analysis and surveys}

This demand analysis, which was conducted in the medium and long-term engineering science and technology development strategy research, confirmed the feasibility of proposing the demands for engineering science and technology from an economic and social development perspective. Because this is the first time the demand analysis panel was established in research on the engineering science and technology development strategy, the number of participants in the survey, including experts on the economy and society, government officials, and entrepreneurs, was limited. However, the opinions of experts on the economy and society, government officials, business people, and managers of leading enterprises and innovative small and medium-sized enterprises were important in the research on the visions and for proposing future economic and social development demands.
Therefore, more of these participants and members of the public should be attracted to participate in future demand analyses and surveys.

\subsection{Attach full importance to vision research}

Based on previous experience in conducting demand analyses domestically and internationally, visions research plays an increasingly important role. The demand analysis carried out in Japan for the country's 10th technology forecast was a science and technology study to realize the structure and visions of the future society. This demand analysis, which formed part of a medium and long-term engineering science and technology development strategy study, also confirmed economic and social development visions research as the basis of a demand analysis. In future visions research work, more people should participate in the survey. Furthermore, methods such as various media including networks should be utilized to gather the visions of various parties.

\section{References}

[1] Chen C. Technology foresight and successful experience in Japan $[\mathrm{J}]$. World Science and Technology Research and Development, 2004, 26 (6): 87-90. Chinese.

[2] Fan X T, Li G Q. Analysis on the development stage and future trend of technology foresight in Japan [J]. Competitive Intelligence, 2016, 12 (3): 37-42. Chinese.

[3] Science and Technology Foresight Center, National Institute of Science and Technology Policy (NISTEP). The 10th science and technology foresight scenario planning from the viewpoint of globalization [R]. Japan: Science and Technology Foresight Center, National Institute of Science and Technology Policy (NISTEP), Ministry of Education, Culture, Sports, Science and Technology (MEXT), 2015.

[4] Government Office for Science. Future of an aging population [R]. UK: Government Office for Science, 2016

[5] Government Office for Science. Future of cities: An overview of the evidence [R]. UK: Government Office for Science, 2016.

[6] Government Office for Science. Future of manufacturing: A new era of opportunity and challenge for the UK [R]. UK: Government Office for Science, 2013.

[7] Wei Q, Bian Y Y. Analysis on the development of technology foresight in world major developed countries [J]. Innovation Science and Technology, 2015 (12): 14-16. Chinese.

[8] Wang Y, Sun F Q. The vision research on economy and society development of country at the end of 12th Five-Year and future [M]. Beijing: Scientific and Technical Documentation Press, 2012. Chinese.

[9] The Research Group of Technology Foresight of China in the Next 20 Years. The technology foresight of China in the next 20 years [M]. Beijing: China Science Publishing \& Media Ltd (CSPM), 2006. Chinese. 